\title{
The promoter of the Chinese hamster ovary dihydrofolate reductase gene regulates the activity of the local origin and helps define its boundaries
}

\author{
Swati Saha, Yujie Shan, Larry D. Mesner, and Joyce L. Hamlin ${ }^{1}$ \\ Department of Biochemistry and Molecular Genetics, University of Virginia School of Medicine, \\ Charlottesville, Virginia 22908, USA
}

\begin{abstract}
The dihydrofolate reductase (DHFR) and 2BE2121 genes in the Chinese hamster are convergently transcribed in late $G_{1}$ and early $S$ phase, and bracket an early-firing origin of replication that consists of a $55-\mathrm{kb}$ zone of potential initiation sites. To test whether transcription through the DHFR gene is required to activate this origin in early $S$ phase, we examined the two-dimension (2D) gel patterns of replication intermediates from several variants in which parts or all of the DHFR promoter had been deleted. In those variants in which transcription was undetectable, initiation in the intergenic spacer was markedly suppressed (but not eliminated) in early $S$ phase. Furthermore, replication of the locus required virtually the entire $S$ period, as opposed to the usual 3-4 h. However, restoration of transcription with either the wild-type Chinese hamster promoter or a Drosophila-based construct restored origin activity to the wild-type pattern. Surprisingly, 2D gel analysis of promoterless variants revealed that initiation occurs at a low level in early $S$ phase not only in the intergenic region, but also in the body of the DHFR gene. The latter phenomenon has never been observed in the wild-type locus. These studies suggest that transcription through the gene normally increases the efficiency of origin firing in early $S$ phase, but also suppresses initiation in the body of the gene, thus helping to define the boundaries of the downstream origin.
\end{abstract}

[Keywords: DNA replication; origins, transcription, mutagenesis]

Received November 21, 2003; revised version accepted January 9, 2004.

With few exceptions (e.g., Sharma et al. 2001), the time in $S$ phase during which eukaryotic origins fire does not appear to be directly regulated by their underlying DNA sequences (Simon and Cedar 1996; for review, see Gilbert 2001). Rather, origin activation is regulated by a variety of other cis- and trans-acting factors. For example, the $\mathrm{X}$ inactivation center (Xic) on the inactive $\mathrm{X}$ chromosome appears to regulate replication timing of that chromosome (Disteche et al. 1979), apparently through expression of its RNA (Keohane et al. 1996). Likewise, sequences in the human $\beta$-globin locus control region (LCR) have been implicated in controlling the time of initiation in the origin located $40 \mathrm{~kb}$ downstream (Forrester et al. 1990; Aladjem et al. 1995; Simon et al. 2001). In Saccharomyces cerevisiae, the telomere functions as a de facto regulatory element, delaying firing of nearby origins (Ferguson and Fangman 1992).

Mammalian genomes are divided into characteristic

${ }^{1}$ Corresponding author.

E-MAIL jlh2d@virginia.edu; FAX (434) 924-5069.

Article published online ahead of print. Article and publication date are at http://www.genesdev.org/cgi/doi/10.1101/gad.1171404. replication-timing zones containing coordinately activated clusters of replicons (Simon and Cedar 1996). DNA within the dark $G$ bands revealed by Giemsa staining replicates late in the S period, whereas DNA in interstitial, light-staining $\mathrm{R}$ bands is usually replicated early (Hand 1978). Because these $\mathrm{G}$ and $\mathrm{R}$ bands correspond to domains of inactive heterochromatin and transcriptionally active euchromatin, respectively, it is assumed that transcriptional activity and initiation of replication somehow regulate one another. Indeed, most actively expressed genes replicate early in S phase (Goldman et al. 1984; Taljanidisz et al. 1989), whereas developmentally regulated genes replicate early in tissues in which they are expressed and later in tissues in which they are silent (Holmquist 1987; Epner et al. 1988; Hatton et al. 1988; Selig et al. 1992). Similarly, the same origins appear to be activated in the early replicating, transcriptionally active human X chromosome as in its late-replicating counterpart (Cohen et al. 2003). Furthermore, homologous alleles that are coordinately expressed usually replicate synchronously, whereas monoallelically expressed genes replicate asynchronously, with the silent allele being duplicated later (Avner and Heard 2001). 
One explanation for the late-replicating pattern of inactive genes in eukaryotic cells might be that transcriptionally inactive chromatin lowers accessibility of the template to components of the replication machinery. Indeed, the yeast transcriptional silencer, Sir3p, which is abundant at telomeres, is also responsible for the latereplicating pattern of sub-telomeric sequences, apparently establishing a heterochromatin-like architecture in the region (Stevenson and Gottschling 1999; Wyrick et al. 1999). However, an analysis of heterochromatic centromeres and silent mating-type cassettes in Schizosaccharomyces pombe shows clearly that both of these elements are early-replicating (Kim et al. 2003). Furthermore, a global analysis of replication timing and transcriptional activity in the $S$. cerevisiae genome found no obvious correlation between the two (Raghuraman et al. 2001). Thus, epigenetic effects on replication timing may differ considerably between lower and higher eukaryotes.

Transcription factors themselves have been shown to accentuate replication initiation in several viral systems, usually by interacting with specific sequences in or near the viral origin to potentiate interaction of initiator proteins with the core origin and/or changing the conformation of the template (for reviews, see Heintz 1992; van der Vliet 1996 and references cited therein). Transcription factors are believed to potentiate initiation in $S$. cerevisiae as well. For example, ABF1-binding sites have been identified in several yeast origins (Buchman et al. 1988) and appear to act in some cases as enhancers (Walker et al. 1991; but see Lin and Kowalski 1997). In Drosophila, a well-known transcription factor $(M y b)$ was recently shown to associate with the replication origin of a chromosome puff and facilitate amplification, much like an enhancer-binding factor in transcription (Beall et al. 2002).

The DHFR initiation zone in Chinese hamster ovary (CHO) cells was the first mammalian origin identified (Heintz and Hamlin 1982; Heintz et al. 1983), and is presently the most thoroughly characterized of the several mammalian origins that have since been localized (Leu and Hamlin 1989; Vaughn et al. 1990; Dijkwel and Hamlin 1995; Pelizon et al. 1996; Kalejta et al. 1998; Kobayashi et al. 1998; Mesner et al. 2003). This origin consists of a zone of $>20$ potential initiation sites distributed throughout the $55-\mathrm{kb}$ spacer between the convergently transcribed 2BE2121 and DHFR genes (Fig. 1A). The efficiency of utilization of these sites varies markedly, with ori- $\beta$, ori- $\beta^{\prime}$, and ori- $\gamma$ being preferred (Fig. 1A; Burhans et al. 1990; Kobayashi et al. 1998; Dijkwel et al. 2002). However, initiation has never been detected in the body of the DHFR gene itself (Vaughn et al. 1990; Dijkwel and Hamlin 1995; P.A. Dijkwel, unpubl.).

Our laboratory is interested in the regulation of initiation in this complex origin. In previous studies, we used a homologous recombination strategy to specifically delete various subregions of the $55-\mathrm{kb}$ intergenic spacer in an effort to identify any required cis-regulatory elements residing within the origin itself (Kalejta et al. 1998; Mesner et al. 2003). Surprisingly, the entire central $45 \mathrm{~kb}$ of the zone could be deleted without affecting the time at which the locus normally replicates in the $S$ period. Interestingly, the preservation of replicating timing was achieved by an increased frequency of initiation in the truncated $10-\mathrm{kb}$ spacer that remained (Mesner et al. 2003). This $45-\mathrm{kb}$ deletion encompasses the region in which $>95 \%$ of initiations occur in the wild-type locus (Leu and Hamlin 1989; Wang et al. 1998; Dijkwel et al. 2002). Therefore, any required cis-regulatory elements must not reside within the origin itself /or if they do, are redundant with other elements that are distributed at very frequent intervals throughout the zone).

These data prompted us to question whether any critical regulatory elements are located outside of the origin itself, perhaps in the promoter of the gene or regions upstream, by analogy to the $\beta$-globin locus (Aladjem et al. 1995). In the present study, we examined the activity of the DHFR origin in various promoter-deficient DHFR variants, most of which were engineered by a homologous recombination strategy. The results of this study suggest that active transcription through the gene, whether fueled by the native or a heterologous promoter, has a dual effect: (1) It increases the efficiency of initiation in the downstream origin, and (2) it completely suppresses initiation in the body of the DHFR gene. Conversely, preventing transcription by removal of the promoter allows the initiation zone to extend into the now silent gene and lowers the efficiency of initiation in the former intergenic spacer.

\section{Results}

DHFR origin activity is suppressed by a large $\gamma$-ray-induced deletion that encompasses the DHFR promoter

The pattern of replication intermediates that characterizes the native DHFR origin in synchronized $\mathrm{CHO}$ cells is shown in Figure 2. Cells were collected at the $G_{1} / S$ boundary by arrest in $\mathrm{G}_{0}$, followed by release into the replication inhibitor, mimosine, for $12 \mathrm{~h}$ (Dijkwel and Hamlin 1995). After release from the $G_{1} / S$ block, cells were harvested at 90, 180, and 360 min (early, mid, and late S phase, respectively; Dijkwel and Hamlin 1995); replication intermediates were isolated using EcoRI to digest the DNA, and the DNA was resolved by a neutral/ neutral two-dimension (2D) gel replicon mapping technique (Fig. 2A; Brewer and Fangman 1987). After transfer to a membrane, replication intermediates were analyzed using a probe specific for the ori- $\beta$ locus (Fig. 1A), one of the most active regions in this broad initiation zone (Leu and Hamlin 1989; Kobayashi et al. 1998; Wang et al. 1998; Dijkwel et al. 2002). As shown in Figure 2B, a composite pattern consisting of a pronounced single fork arc and a complete bubble arc is detectable in early $S$ phase $(90 \mathrm{~min})$. This pattern is displayed by initiation sites within large zones of potential sites, because in some cells the fragment sustains an internal initiation event, whereas in most cells it is replicated passively by forks emerging from other initiation sites within the 


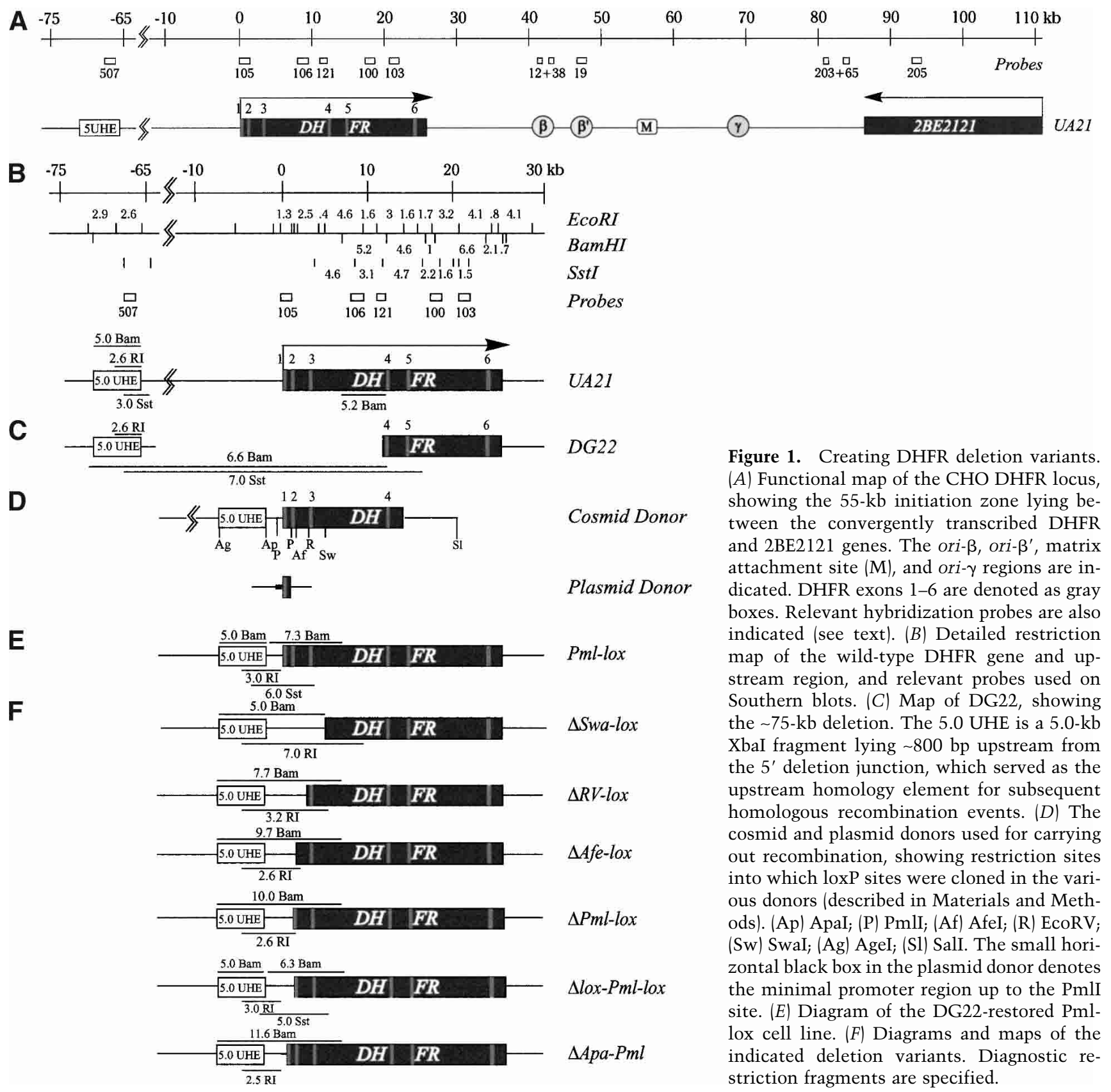

zone (Vaughn et al. 1990; Dijkwel and Hamlin 1995). Initiation is largely complete by $180 \mathrm{~min}$ in $\mathrm{S}$ phase, although the single fork arc persists. By $360 \mathrm{~min}$, most replication intermediates have cleared from the locus.

To examine whether transcription through the DHFR gene is required for the activity of the downstream origin, we analyzed the origin in the promoterless DHFRdeficient cell line DG22 (Urlaub et al. 1983). This $\gamma$-rayinduced variant has sustained a deletion that extends $\sim 75 \mathrm{~kb}$ upstream of the approximate center of the DHFR gene (Fig. 1C). As we show below, no DHFR-specific transcripts can be detected in DG22. When replication intermediates were harvested from synchronized DG22 cells and the ori- $\beta$ locus was analyzed on a $2 \mathrm{D}$ gel, the pattern was very different from that observed in wildtype $\mathrm{CHO}$ cells (Fig. 2C, upper panels). Single fork arcs of almost equal intensity were detected at all time points tested, unlike the wild-type situation, in which many more intermediates populate the origin in early $S$ phase than in late $S$ phase (Fig. 2B). When the transfer was stripped and rehybridized with probe 19 for the ori- $\beta^{\prime}$ locus or probes $203+65$ for the $3^{\prime}$-end of the zone in DG22, almost identical patterns were obtained (Fig. 1A; data not shown). Upon reprobing the transfer for the rhodopsin origin (which resides on another chromosome and, like the DHFR origin, consists of a broad zone of potential initiation sites; Dijkwel et al. 2000), the wildtype early-firing pattern of initiation was observed (Fig. 
A

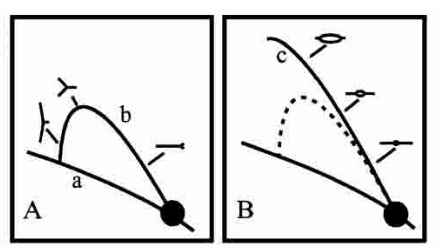

B

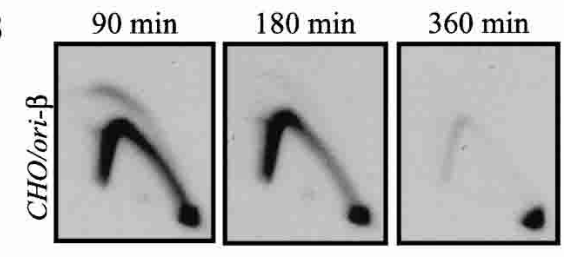

C

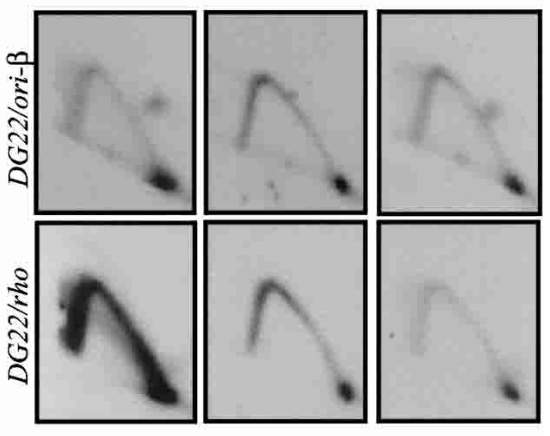

D

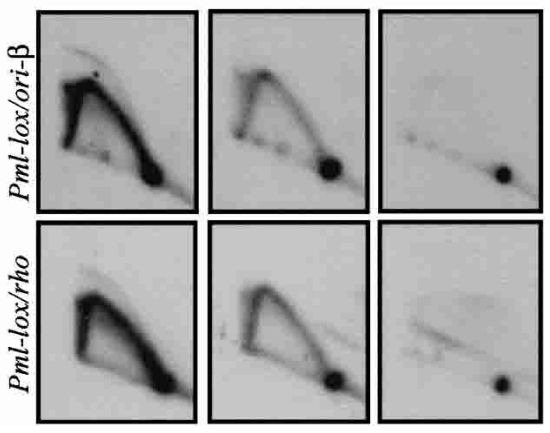

Figure 2. Neutral-neutral 2D gel analysis of replication intermediates from the CHO, DG22, and the restored Pml-lox cell lines. (A) Diagram of characteristic patterns traced on neutral/ neutral 2D gels by fragments containing single forks (left panel) or centered replication bubbles (right panel). (a) The arc of linear DNA fragments; (b) the single fork arc; (c) the centered bubble arc. (B) EcoRI-digested replication intermediates were isolated from $\mathrm{S}$ phase $\mathrm{CHO}$ cells at the indicated times after synchronization, separated on a $2 \mathrm{D}$ gel, transferred to a membrane, and analyzed with probes for the ori- $\beta(12+38)$ locus. $(C)$ Patterns obtained from DG22 DNA with the ori- $\beta$ probe (upper panels) and after stripping and rehybridization with a probe for the early firing rhodopsin origin (rho; lower panels). (D) 2D gel patterns obtained for Pml-lox, in which the missing 5 '-end of the gene and the $1.9-\mathrm{kb}$ promoter region upstream have been restored by homologous recombination as shown in Figure 1C and D.

2C). The rhodopsin origin thus serves as an internal control on cell synchrony and the quality of DNA preparations. Therefore, the $\sim 75-\mathrm{kb}$ deletion in DG22 somehow has suppressed initiation in the DHFR origin in early $S$ phase.
Restoration of the 5'-end of the DHFR gene and promoter without the upstream sequences in the DG22 deletion restores wild-type DHFR origin activity

The DG22 deletion encompasses $\sim 9.5 \mathrm{~kb}$ of the DHFR gene and $\sim 65 \mathrm{~kb}$ upstream. To determine whether the effects on the replication pattern in DG22 result from loss of DHFR sequences per se, we devised a homologous recombination strategy to restore the missing part of the gene and promoter region but not the $\sim 65 \mathrm{~kb}$ upstream (Fig. 1C,D). A 5-kb upstream homology element 15.0 UHE) was cloned into the cosmid $\mathrm{cH}-2$ (Fig. 1D), and this donor construct was transfected into DG22 cells. Potential homologous recombinants that had restored the gene to the wild-type configuration were selected on minimal medium (Urlaub et al. 1983), as described in Materials and Methods. (Bacterial lox site pairs straddling defined sequences in and near the DHFR promoter were engineered into several other cosmid donors to facilitate a series of Cre-mediated deletions; see below.)

Several survivors were isolated, and homologous recombinants were identified by Southern blotting and hybridization with relevant probes. The results for one of the survivors (Pml-lox) are presented in Figure 3. Recombination with the donor in the 5.0 UHE and somewhere within the $3^{\prime}$-half of the gene (Fig. 1C,D) results in the disappearance of a 6.6-kb BamHI deletion junction fragment and the appearance of restored fragments 5.0 and $5.2 \mathrm{~kb}$ in length, which can be detected with probes 507 and 121 (Figs. 1B, 3A,B), respectively. Probe 105, a 1.3-kb EcoRI fragment spanning the 3 '-half of the promoter and $5^{\prime}$-end of the gene, finds no counterpart in DG22 but detects a 7.3-kb fragment in the Pml-lox recombinant restored with the donor construct (Fig. 3D). In EcoRI and Sst1 digests, probe 507 illuminates $2.6-\mathrm{kb}$ and $7.0-\mathrm{kb}$ fragments, respectively, in DG22, and the predicted 3.0$\mathrm{kb}$ and 6.0-kb fragments in Pml-lox (Fig. 3A,C).

Thus, Pml-lox contains a faithfully restored wild-type DHFR gene and $\sim 1.9 \mathrm{~kb}$ of sequence upstream of the AUG start codon, but lacks the remaining $63 \mathrm{~kb}$ deleted in DG22. When replication intermediates in the ori- $\beta$ locus in Pml-lox were examined by the 2D gel replicon mapping strategy, the pattern obtained was nearly identical to that of the early-firing rhodopsin origin (Fig. 2D, upper and lower panels, respectively). Similar wild-type patterns were observed with probe 19 for ori- $\beta^{\prime}$ or probes $203+65$ for the far end of the initiation zone (Fig. 1A; 2D gel data not shown). Hence, the sequences whose loss elicits the aberrant pattern of initiation in DG22 must reside within the restored $5^{\prime}$-end of the gene and $1.9 \mathrm{~kb}$ upstream.

\section{Deletion analysis of the $5^{\prime}$-end of the DHFR gene}

To define the critical sequence elements residing within the 5 '-end of the gene and the region upstream of it, a series of deletion variants was constructed using the engineered donor cosmids described in Materials and Methods. The donors in each case contained a wild-type promoter except for the presence of the two 35-bp lox 
A
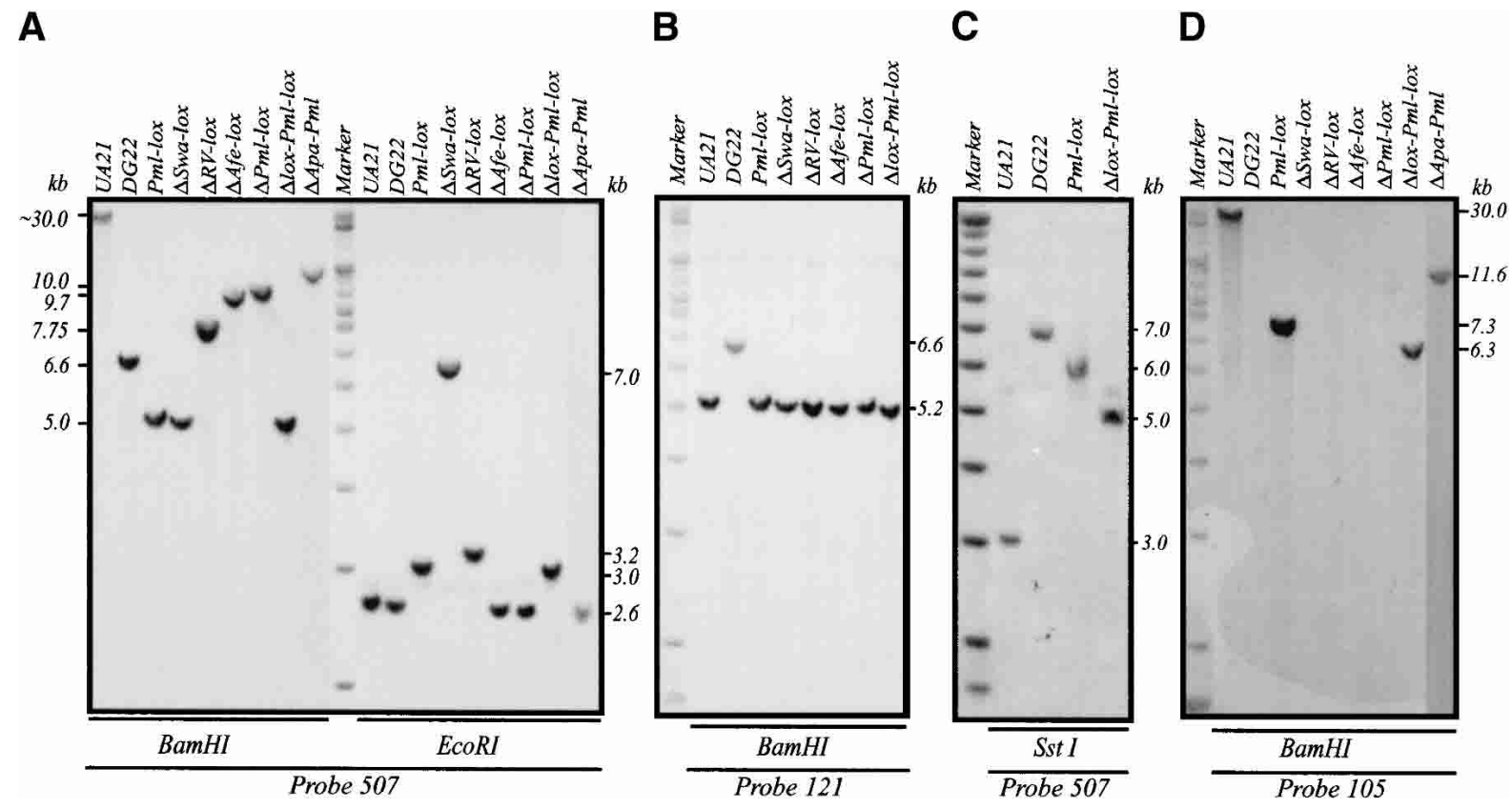

Figure 3. Southern blot analysis of DG22, Pml-lox, and the various promoter-deficient variants. (A) BamHI- and EcoRI-digested genomic DNA analyzed with probe 507. (B) BamHI-digested DNA analyzed with probe $121 .(C)$ SstI-digested DNA analyzed with probe 507. (D) BamHI-digested DNA analyzed with probe 105.

sites flanking the targeted deletion. This allowed DHFR gene expression and selection on minimal medium when faithful homologous recombination occurred between the donors and the truncated DG22 locus. The genomic DNA arrangements in surviving colonies were characterized by Southern blotting as described above for Pmllox. Once clean homologous recombinants of each type were isolated, a Cre recombinase-expressing plasmid was transfected into each cell line, and the loss of sequences flanked by the two lox sites was confirmed by Southern blotting (Fig. 3). Probe 105 containing the DHFR promoter recognizes its counterpart in the restored cell line, Pml-lox, but fails to detect sequences in all the promoter dropouts except $\Delta \mathrm{Apa}-\mathrm{Pml}$ and $\Delta$ loxPml-lox (Fig. 3D). $\Delta$ Apa-Pml retains the $5^{\prime}$-end of the gene and gene-proximal $0.55 \mathrm{~kb}$, but not the $1.35 \mathrm{~kb}$ upstream. $\Delta$ lox-Pml-lox retains the sequences deleted in $\Delta$ Apa-Pml but lacks almost the entire first intron, first exon, and $0.55 \mathrm{~kb}$ upstream of the start codon. The latter region encompasses the DHFR minimal promoter as defined by in vitro transcription assays with DHFR minigene constructs (Farnham and Schimke 1986; Azizkhan et al. 1993).

\section{Effects of promoter deletions on DHFR origin activity}

Using these DHFR-deficient variants, we investigated whether DHFR origin activity depends on local transcriptional activity. With the exception of $\Delta$ Apa-Pml, which retains the minimal promoter (Fig. 1F), the deletion variants were all predicted to completely suppress transcription in the DHFR gene. When each variant was analyzed by the 2D gel mapping procedure, the resulting patterns were of two types. The first was an aberrant pattern for the ori- $\beta$ locus similar to that displayed by DG22, and is exemplified by the $\Delta$ Pml-lox variant shown in Figure 4B (upper panels). The promoterless $\Delta$ Swa-lox, $\Delta \mathrm{RV}$-lox, and $\Delta$ Afe-lox cell lines also displayed this aberrant pattern (data not shown). Similar aberrant patterns were obtained with probes 19 and with probes $203+65$ (Fig. 1A; data not shown). In contrast, the $\Delta$ loxPml-lox and $\Delta$ Apa-Pml cell lines each displayed the wild-type early-firing pattern, as shown in Figure 4C and $\mathrm{D}$ (cf. Pml-lox in Fig. 4A; note that the $\Delta$ Apa-Pml transfers are somewhat underexposed relative to the other samples). Therefore, deletions that included the first intron and exon, the minimal promoter, and the region extending upstream from the minimal promoter to the 5.0 UHE resulted in the aberrant pattern. However, deletion of the minimal promoter, the first intron, and first exon had no discernible effect on the wild-type earlyfiring origin pattern (Fig. 4C); neither did deletion of the $1.35 \mathrm{~kb}$ immediately upstream from the minimal promoter (Fig. 4D).

The wild-type initiation pattern of the DHFR origin appears to depend on transcriptional activity through the gene

The deletions in $\Delta$ lox-Pml-lox and $\Delta$ Apa-Pml together encompass the deletion in $\Delta \mathrm{Pml}$-lox, yet neither one displays the aberrant pattern that characterizes $\Delta \mathrm{Pml}-1$ lox. This observation raised the possibility that redundant elements separated by the deletions in $\Delta$ lox-Pml-lox and 
Saha et al.

A

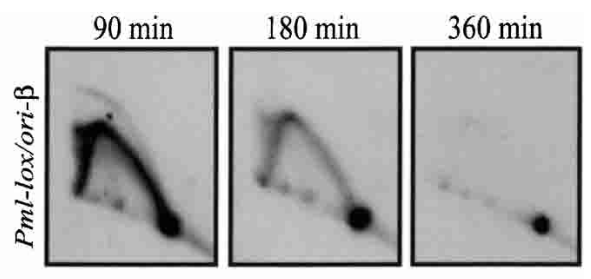

B
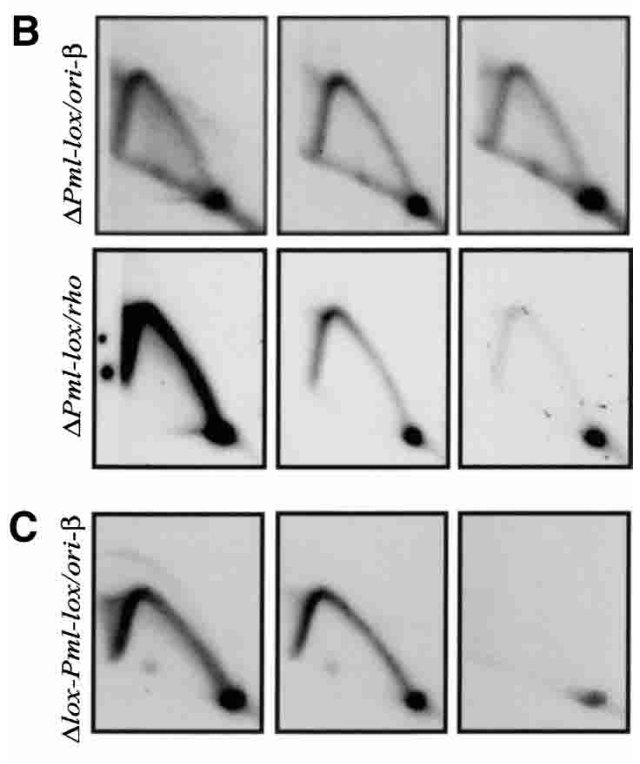

D

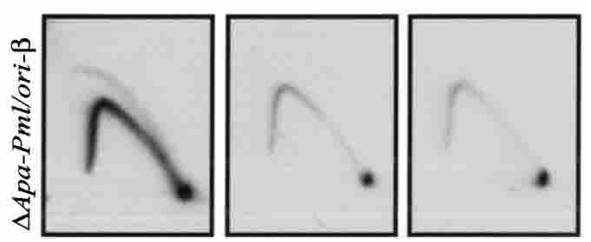

Figure 4. Deletion of the $1.9-\mathrm{kb}$ promoter region, but not the minimal promoter, results in an aberrant pattern of initiation. (A) Two-dimensional gel pattern for the restored Pml-lox cell line probed at ori- $\beta$. (B) Two-dimensional gel pattern for $\Delta$ Pmllox probed at ori- $\beta$ and the rhodopsin origin. $(C, D)$ Two-dimensional gel patterns for $\Delta$ lox-Pml-lox and $\Delta$ Apa-Pml probed for ori- $\beta$ (see Fig. 1F).

$\Delta$ Apa-Pml (Fig. 1F) might play an important role in modulating origin activity, possibly through mechanisms unrelated to transcription per se. It was therefore important to determine how the various deletions affected transcription through the DHFR gene. Total RNA was isolated $90 \mathrm{~min}$ after entry into $S$ phase from the same cultures used to prepare the 2D gels in Figure 4 and were subjected to RT-PCR.

DHFR-specific transcripts were analyzed with primer sets from the region of probes 100 and 103. Primer sets 205 and rps14 served as controls for the opposite strand 2BE2121 transcript and a ribosomal protein gene (Rhoads and Roufa 1991), respectively. As shown in Figure 5, significant levels of DHFR-specific transcripts were detected in Pml-lox, $\Delta$ Apa-Pml, and, surprisingly, $\Delta$ loxPml-lox with both primer sets; in contrast, only a faint background signal could be detected in RNA from DG22 or $\Delta$ Pml-lox (the RR primer sets in Fig. 5; cf. background signals obtained with the opposite strand primers FF; note that similar background levels were obtained with non-RT controls). Reactions containing genomic DNA from the various cell lines confirmed that sequences complementary to the PCR primers were actually present in the genomes (data not shown). Therefore, all of the cell lines that display significant levels of transcription (including $\Delta$ lox-Pml-lox, which has deleted the minimal promoter) also display the wild-type pattern of initiation in the downstream origin.

\section{A heterologous eukaryotic promoter can substitute for the native DHFR promoter to impart wild-type origin activity}

Although a positive correlation exists between transcription and active initiation in the DHFR origin in early $S$ phase, we could not rule out the possibility that redundant sequence elements residing in the region upstream of the gene perform a function unique to replication initiation. We therefore tested whether a heterologous eukaryotic promoter could substitute for the wild-type DHFR promoter in activating the downstream origin in early S phase. A Drosophila-based ecdysone-inducible heat-shock promoter system was used to restore the DHFR gene in DG22 (Fig. 6A; Invitrogen). In this system, the inducing hormone, ponasterone A, causes heterodimerization of the two hormone receptor subunits, and the dimerized receptor activates the heat-shock promoter via its upstream hormone response elements. Pairwise BLAST alignment revealed no sequence similarity between this chimeric promoter and the native DHFR promoter.

A donor plasmid was engineered to contain the heatshock promoter and hormone-response elements positioned just upstream from exon 1 of the DHFR gene, with the entire cassette flanked by lox sites (Fig. 6A). This was cotransfected into the promoter-deficient $\Delta$ Pml-lox cells along with a Cre recombinase-expressing plasmid and a second plasmid encoding the two regulatory hormone subunits. DHFR ${ }^{+}$survivors were selected in F12-special medium (which lacks hypoxanthine and thymidine) containing ponasterone A. As a control, the donor plasmid was cotransfected with the Cre expression plasmid alone and plated as above. As expected, no $\mathrm{DHFR}^{+}$colonies were obtained in the absence of the hormone receptor subunits. Southern analysis of an Asp 718/SmaI digest of DNA from the VgRxR/EGREshsp/ $\Delta$ Pml-lox cell line confirmed that the $15.6-\mathrm{kb}$ Asp 718 fragment in $\Delta$ Pml-lox had been replaced by the $11.6-\mathrm{kb}$ SmaI/Asp 718 fragment predicted for the recombinant (Fig. 6A,B).

RT-PCR was then performed on total RNA isolated from log-phase cultures of the recombinant cell line in the presence and absence of the inducer. Surprisingly, relatively comparable levels of DHFR-specific transcript were detected after 40 cycles of PCR amplification whether or not the inducer was present in the growth medium (Fig. 6C). Moreover, the Drosophila promoter 


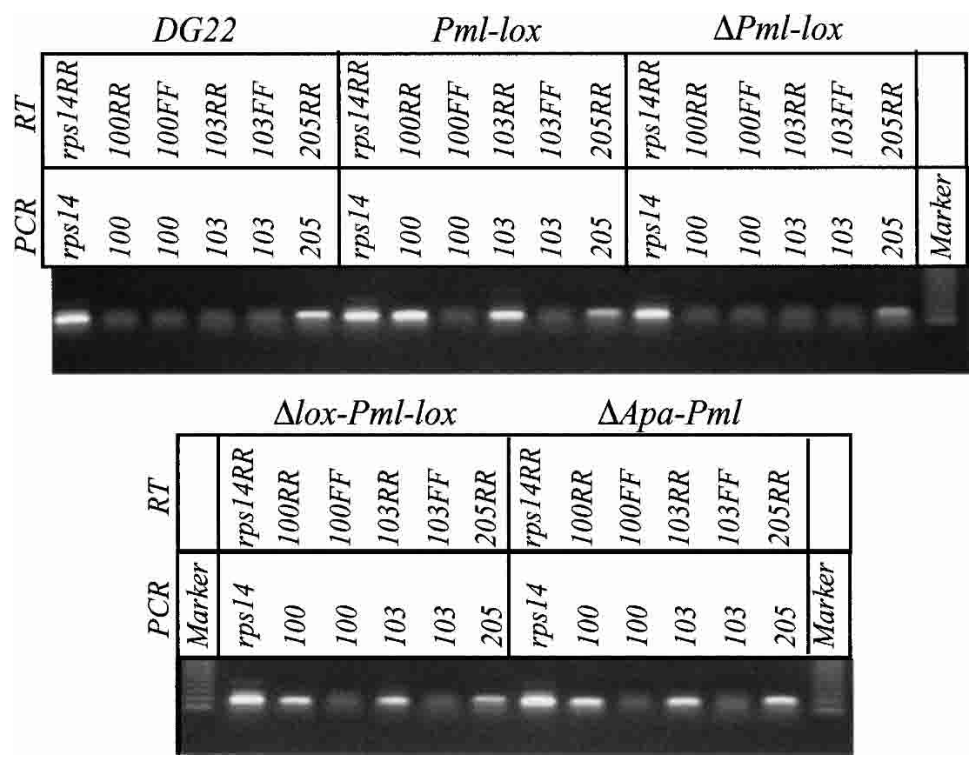

Figure 5. Analysis of primary DHFR-specific transcripts in DG22 and various homologous recombinants. RNA was isolated from the indicated cell lines, and subjected to reverse transcription, followed by PCR amplification for 40 cycles using the indicated primer pairs. The RR primer sets are specific for the transcribed strand of the DHFR and 2BE2121 genes, and the FF sets are specific for any RNA arising from the opposite strand. The marker is the 123-bp ladder (Invitrogen). See Figure 1A for primer positions. was sufficiently leaky to allow survival in minimal medium without ponasterone A (data not shown). Importantly, in the absence of inducer, the downstream ori- $\beta$ locus in VgRxR/EGREshsp/DPml-lox displayed the distinct wild-type initiation pattern (Fig. 6D; cf. rhodopsin). Thus, the Drosophila promoter provides the necessary elements to activate transcription as well as initiation in the downstream origin.

The replication profiles of the DHFR gene in the deletion variants differ significantly from that of the wild-type DHFR locus

Although the pattern of initiation in each of the promoterless variants differs considerably from wild type, this aberrant pattern is not a true late-replicating pattern. In Figure $7 \mathrm{~A}$ and $\mathrm{B}$, the $2 \mathrm{D}$ gel results for ori- $\beta$ in the promoterless $\Delta$ Pml-lox cell line are compared with DR-8, a hemizygous DHFR-deficient variant lacking the 3 '-end of the DHFR gene (Jin et al. 1995). In DR-8, there is almost a total lack of replication intermediates at 90 min, both at ori- $\beta$ and in the body of the DHFR gene, regardless of film exposure times or amounts of material loaded onto the gels (Kalejta et al. 1998; L.D. Mesner, unpubl.; also see Discussion). In contrast, $\Delta$ Pml-lox displays virtually the same (relatively low) number of intermediates at $90 \mathrm{~min}$ as it does at 180 and $360 \mathrm{~min}$. However, in both cell lines, single fork arcs persist in the region of ori- $\beta$ well into late $S$ phase (Fig. 7, $360 \mathrm{~min}$ ).

Insight into the nature of the initiation defect in promoterless variants such as $\Delta$ Pml-lox was provided by a time-course analysis of fragments both within the intergenic region itself and in the body of the DHFR gene. As shown in Figure 8A, at 90 min into $S$ phase, when active initiation is occurring in the intergenic region in the wild-type situation (Pml-lox in this case; upper panels), very few forks have yet entered the DHFR gene (detected with probes 103 and 106; Fig. 8A, middle and lower pan- els). By $180 \mathrm{~min}$, single fork arcs arriving from the intergenic initiation zone are now more prominent at the positions of both of these probes, and by $360 \mathrm{~min}$, all replication intermediates have essentially cleared from the locus (Fig. 8). In contrast, the promoterless $\Delta$ Pml-lox (Fig. 8B) displays about the same amount of single forks in the body of the gene (probes 103 and 106) as in the ori- $\beta$ region at $90 \mathrm{~min}$ and, indeed, at all three time points sampled. The same pattern was obtained with probe 19 and probes $203+65$ (data not shown).

For replication forks to populate the DHFR gene as early as $90 \mathrm{~min}$ in the promoterless $\Delta$ Pml-lox cell line, it seemed likely that initiation actually might be occurring within the body of the gene in early $S$ phase. To investigate this possibility, the $2 \mathrm{D}$ gel analysis was repeated on Pml-lox and $\Delta$ Pml-lox, using larger numbers of synchronized cells and optimizing the time of sampling in early S phase. Cells harvested at 70, 80, and 90 min after release from mimosine displayed approximately the same quantity and distribution of intermediates, and the results for the 70-min time point are shown in Figure 9. (Note that, due to the faintness of the bubble arcs in this broad initiation zone, coupled with the decay of synchrony as cells traverse $S$ phase, we were not able to determine whether initiation also occurs in this origin in mid and late $S$ phase.)

As can be seen (Fig. 9A), a probe for the body of the gene (probe 103) detects very few intermediates at 70 min in Pml-lox DNA, whereas probes $12+38$ illuminate the typical composite pattern at ori- $\beta$. Thus, initiation in the intergenic region is actively occurring at $70 \mathrm{~min}$ in Pml-lox, but very few replication forks have yet reached the gene. However, in $\Delta \mathrm{Pml}$-lox, composite patterns consisting of faint bubble arcs and strong single fork arcs are detected both in the gene and at ori- $\beta$ (Fig. 9B; note that about twice the number of intermediates were loaded in Fig. 9B as in Fig. 9A). When larger numbers of intermediates from Pml-lox were separated on a gel, probed for 
Saha et al.

Figure 6. A heterologous eukaryotic promoter drives transcription through the DHFR gene and activates the DHFR origin in early $S$ phase. (A) The heterologous Drosophila promoter (donor) was inserted into $\Delta \mathrm{Pml}-\mathrm{lox}$ cells by Cre-mediated recombination to create the cell line, VgRxR/EGREshsp/ $\Delta$ Pml-lox (see Materials and Methods). (Closed triangles) loxP sites; (E1) DHFR exon 1; (I1) 80 bp of DHFR intron 1; (hsp) heat-shock promoter; (E/GRE) ecdysone/glucocorticoid hybrid response element. Diagnostic restriction fragments created and the probe used to detect them are indicated. (B) Southern blot analysis of VgRxR/EGREshsp/DPml-lox. Asp 718-SmaI-digested DNA was analyzed with probe 121. (C) RT-PCR analysis of DHFR transcripts in the presence and absence of ponasterone A. (rps14) ribosomal protein S14; (100) DHFR gene; (205) 2BE2121 gene. (D) Two-dimensional gel analysis of the VgRxR/ EGREshsp/ $\Delta$ Pml-lox cell line sampled at the indicated times after release from mimosine arrest and analyzed using probes for ori- $\beta$ and for the control rhodopsin origin.
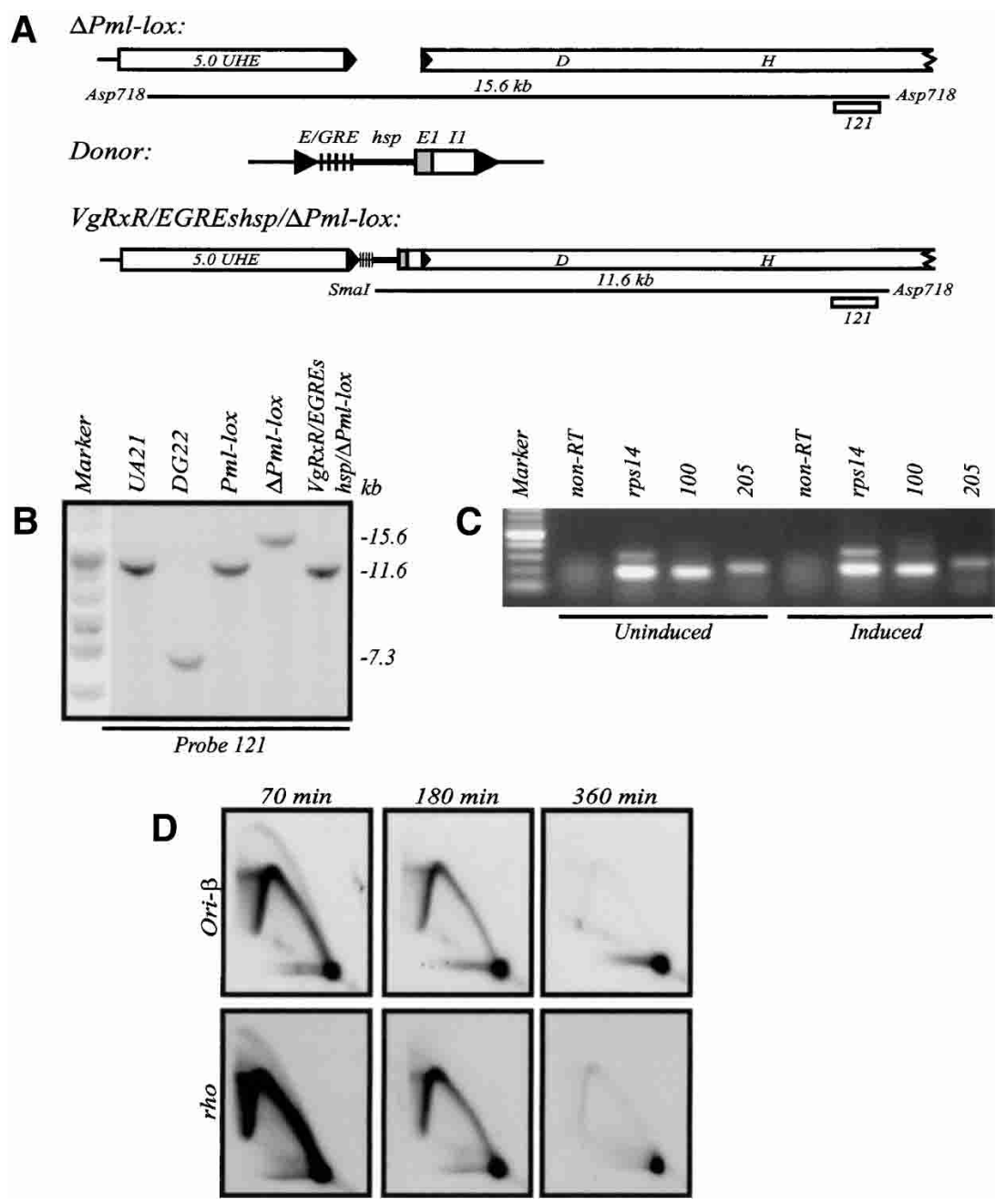

the gene, and exposed so that the fork arc was approximately the same intensity as that of $\Delta$ Pml-lox, no bubbles could be detected (Fig. 9C). This is consistent with every other experiment performed on wild-type cell lines, in which we have never detected bubbles in the body of the gene at any film exposures (Vaughn et al. 1990; Dijkwel and Hamlin 1995; P.A. Dijkwel, unpubl.). It thus appears that deleting the DHFR promoter causes the initiation zone to spread from the former intergenic region into the now silent gene.

\section{Discussion}

Many investigations have revealed a strong correlation between replication and transcription in eukaryotic cells (for review, see Goren and Cedar 2003). A recent genome-wide analysis of Drosophila melanogaster compared the replication timing of $>5000$ genes with their expression profiles (Schubeler et al. 2002), and found that almost $80 \%$ of the early-replicating genes were expressed. The study described in the present report investigates whether transcription modulates initiation in the CHO DHFR origin of replication, and, if so, how. Impor- tantly, transcription of both the DHFR and 2BE2121 genes occurs primarily in late $G_{1}$ and early $S$ phase, bracketing the interval during which this origin normally fires.

We were aided by the availability of DG22, a cell line that lacks the DHFR promoter and upstream sequences because of a large $\gamma$-ray-induced deletion (Urlaub et al. 1983). DHFR-specific transcripts were not detected in DG22, and its origin of replication displayed an aberrant pattern of initiation in which the characteristic burst of initiation that occurs in the wild-type locus in early $S$ phase was not detected; instead, low but approximately constant levels of replication intermediates were observed throughout the S period (Fig. 2). Restoring the 5 '-half of the gene and sequences immediately upstream demonstrated that the responsible elements reside within the promoter region and not the remaining $63 \mathrm{~kb}$ of the deletion. The same aberrant initiation phenotype was recapitulated in smaller, targeted, promoter deletions lacking detectable DHFR transcripts ( $\Delta$ Swa-lox, $\Delta \mathrm{RV}$-lox, $\Delta$ Afe-lox, and $\Delta$ Pml-lox; Figs. 1F, 4).

We anticipated that the $\Delta$ lox-Pml-lox cell line would also display the aberrant-origin phenotype. However, a 


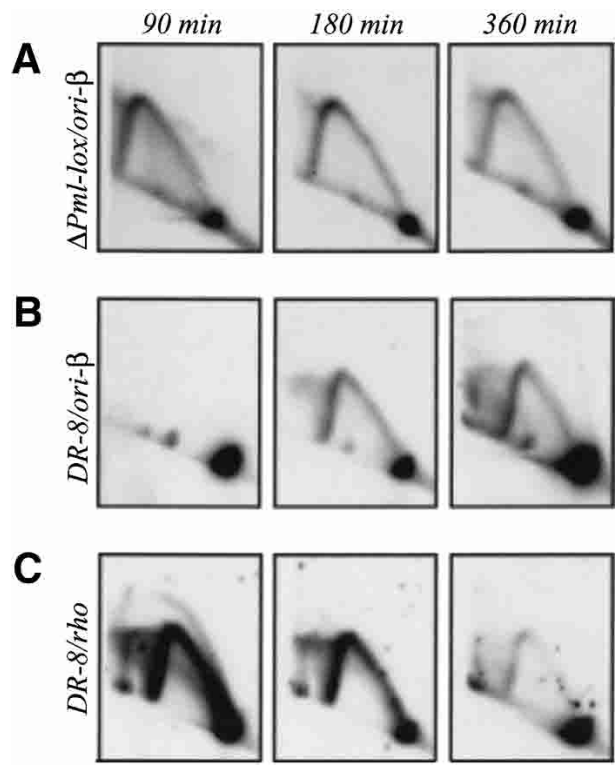

Figure 7. The pattern of replication intermediates in $\Delta$ Pml-lox differs from the late-replicating pattern displayed by the DR-8 cell line. (A) Two-dimensional gel pattern for replication intermediates from synchronized $\Delta \mathrm{Pml}$-lox cells sampled at the indicated times and probed for ori- $\beta$ (see rhodopsin control in Fig. $4 \mathrm{~B}) .(B, C)$ Two-dimensional gel patterns for the DR-8 cell line probed for ori- $\beta$ or the early firing rhodopsin control origin, respectively.

significant level of transcripts was still detected (Fig. 5), and 2D gel analysis of the origin revealed the wild-type, early-firing pattern of initiation. Results from the various deletion variants (Fig. 1F) indicated that the sequences in $\Delta$ lox-Pml-lox responsible for both transcription and early-firing origin activity must reside in the region just upstream of the minimal promoter and not within the 5.0 UHE or sequences on its $5^{\prime}$-side, because the latter are present in $\Delta$ Swa-lox, $\Delta \mathrm{RV}$-lox, $\Delta$ Afe-lox, and $\Delta$ Pml-lox, none of which transcribe the gene. Likewise, the sequences in exon 1 and intron 1 cannot by themselves promote the wild-type transcription and initiation activities, because they are deleted in $\Delta$ lox-Pmllox.

Therefore, the two parts of the promoter region (represented by the deletions in $\Delta$ lox-Pml-lox and $\Delta$ Apa-Pml) play functionally redundant roles in modulating both transcription and origin activity. A pairwise BLAST alignment revealed no obvious similarities between the two. Thus, the question arises how they might function. Insight was provided by the observation that $\Delta \mathrm{Pml}$-lox cells, which do not transcribe the gene and display the defective origin pattern on 2D gels, could be restored to wild-type promoter and origin activity with a Drosophila-based heterologous promoter cassette that shares no obviously similar sequence motifs with the DHFR promoter. Because this complex chimeric promoter was active even in the absence of inducer, we could not determine whether the act of transcription per se is required to mediate effects on the downstream ori- gin. However, the origin displayed full early-firing activity (Fig. 6). Note also that the Drosophila-based promoter cassette did not drive DHFR gene expression when the hormone receptor subunits were not supplied in trans (data not shown). Therefore, we conclude that a heterologous eukaryotic promoter and its cognate trans-acting factors can fully substitute for the DHFR promoter and its associated factors in coordinately regulating transcription and origin activation in early $\mathrm{S}$ phase.

Based on the many studies in which transcriptionally inactive genes or chromosome domains have been shown to be late-replicating, we might have expected that complete suppression of transcription through the DHFR gene in promoterless variants would render the DHFR origin incapable of firing in early S phase. Instead, the phenotype we discerned is more subtle (Fig. 7). First of all, the efficiency of initiation within the former intergenic region in early $\mathrm{S}$ phase is reduced but not eliminated: when high concentrations of intermediates were examined on 2D gels, faint bubble arcs still could be detected at the ori- $\beta$ locus (Fig. 9); furthermore, complete replication of this locus appears to require far longer than $6 \mathrm{~h}$ (Fig. 4B), as opposed to the $\sim 4 \mathrm{~h}$ required by wild-type cells (Fig. 2B). Secondly, 90 min into S phase, the overall level of replication intermediates in the body of the DHFR gene is as high as that of the intergenic region, compared with the wild-type situation in which few intermediates of any kind populate the gene at $90 \mathrm{~min}$ (Fig. 8). Significantly, bubble arcs can be detected in the body of the gene in promoterless variants-something that has never been observed in wild-type cells (Fig. 9).

The implications of these observations are twofold: (1) The lack of transcription allows the body of the DHFR gene to become a template for initiation, and suggests that virtually any DNA sequence in the genome of mammalian cells can serve as an origin provided that it is in a permissive chromosomal environment; and (2) the overall efficiency of initiation in the DHFR locus is clearly reduced in the absence of an active promoter.

The first of these implications is supported by the phenotype of the DR- 8 cell line, in which the 3 '-end deletion results in complete suppression of initiation in the ori- $\beta$ region. Work in progress in our laboratory shows that DHFR transcription in DR-8 proceeds at least as far as ori- $\beta$, suggesting that transcription through a template excludes its use as a substrate for initiation of replication (L.D. Mesner, unpubl.).

It is difficult to imagine that the presence of transcription complexes per se interferes with the loading of replication initiation complexes even in the most actively transcribed genes, as this would seem to require almost total coverage of the gene by the transcription machinery at all times during the window of initiation in early $S$ phase. However, in S. cerevisiae, a regulatable promoter has been used to show that active transcription through a yeast replicator (ARS1) on a plasmid does prevent the origin from firing efficiently (Snyder et al. 1988). Unfortunately, we have not yet identified a heterologous promoter that could be adequately regulated in $\mathrm{CHO}$ cells to effect complete abolition or activation at will; this 
Saha et al.

A

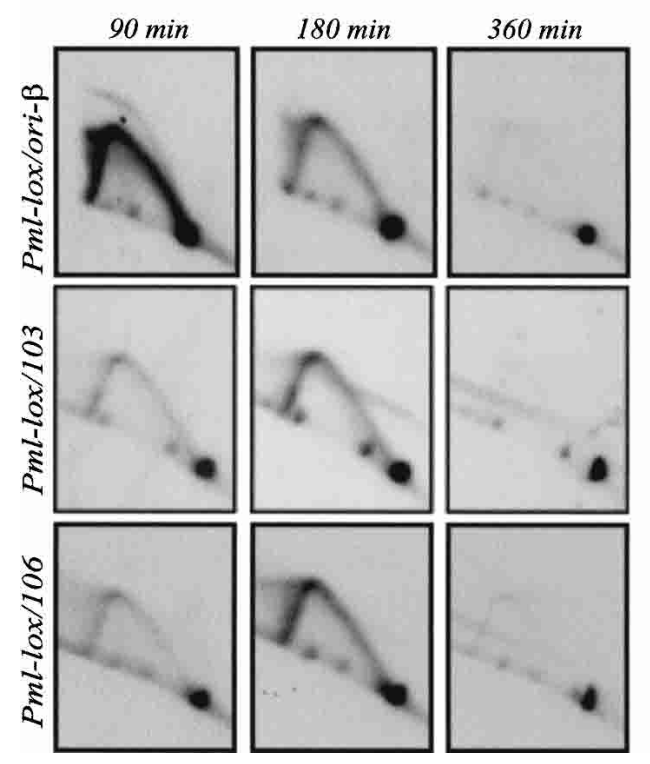

B

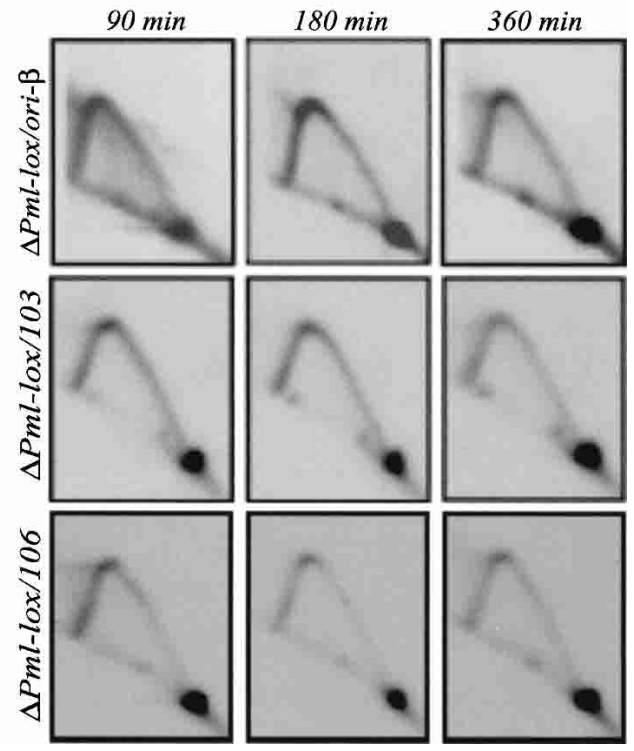

Figure 8. Replication intermediates appear in the DHFR gene earlier in the promoterless $\Delta$ Pml-lox cell line than in the promotercontaining Pml-lox. Replication intermediates from Pml-lox $(A)$ or $\Delta$ Pml-lox $(B)$ cell lines were sampled at the indicated times in $S$ phase and separated on a $2 \mathrm{D}$ gel. The ori- $\beta$ locus and two different positions in the DHFR gene (see Fig. 1A) were analyzed using probes $12+38,103$, or 106, respectively, in successive hybridizations of the same transfer. Films were exposed to yield similar intensities of the $1 n$ spots in each case.

would have allowed us to distinguish between acute versus long-term effects of transcription on initiation in the downstream origin. A related model is that prereplication complexes are assembled almost uniformly throughout the genome in early $G_{1}$, but when transcription commences in active genes, are removed from the template, with the result that only intergenic regions usually serve as origins (Gilbert 2001). This would explain why $\mathrm{CHO}$ nuclei initiate replication throughout the DHFR gene and intergenic region when they are isolated from early $G_{1}$ cells, but initiation is confined to the intergenic region when they are isolated in late $G_{1}(\mathrm{Wu}$ and Gilbert 1996).

Studies in other model systems suggest that more global, highly regulated changes in chromatin environment mediate the interaction between transcription and local origin activity. For example, an upstream locus control region (LCR) in the mammalian $\beta$-globin locus consists of a series of redundant elements that regulate both transcription and replication initiation activity (Forrester et al. 1990). Presumably, such elements (and possibly the DHFR promoter) could be used to load replication initiation factors, to be delivered to the origin region by looping (Su et al. 1991; Yoshida et al. 1999). Alternatively, the LCR and the DHFR promoter might load chromatinremodeling factors that render their respective loci permissive for both transcription and replication initiation. At present, it is not clear whether active transcription per se or transcription-coupled events such as histone modification modulate DHFR origin activity. Until we can devise a regulatable promoter for the DHFR gene that allows us to eliminate transcription acutely without deleting elements of the promoter, it will be difficult to uncover direct effects of histone modification on initiation of replication as opposed to indirect effects resulting from the act of transcription.

Observations similar to those on the DHFR locus have been made in Xenopus laevis embryos, in which, prior to the onset of transcription at the mid-blastula transition $(\mathrm{MBT})$, replication initiates at random sites distributed throughout the rDNA locus, including the body of the inactive rDNA genes; after the MBT when transcription commences, initiation is confined to the intergenic spacers (Shiokawa et al. 1981; Hyrien et al. 1995). Similar modulations of initiation activity have been detected in the Drosophila pol $\alpha$-dE2F locus pre- and postcellularization (Sasaki et al. 1999), as well as in the Sciara coprophila II/9A locus at the onset of transcription (Lunyak et al. 2002). In these situations, the unfolding developmental program surely must orchestrate changes in chromatin environment in the region of the inchoate promoters so that they can be bound by the relevant transcription factors. For example, classic early studies demonstrated a developmentally regulated change in chromatin structure in the promoter of the $\beta$-globin gene long before the gene was actually activated (Weintraub et al. 1981). On a larger scale, in both Xenopus and Drosophila embryos, chromatin appears to have a more open configuration prior to the MBT and pre-blastoderm stages, respectively, apparently owing to the absence of histone $\mathrm{H1}$ (Elgin and Hood 1973); conceivably, this could facilitate the loading of pre-RCs at random sites, including the bodies of inactive genes, which could then be displaced at a later time by advancing transcription complexes. 


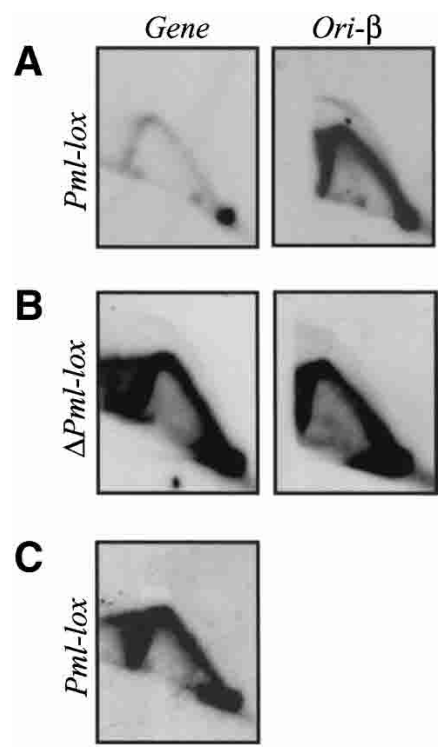

Figure 9. Deleting the functional DHFR promoter allows the initiation zone to spread into the body of the DHFR gene. $(A)$ Pml-lox cells were synchronized as described and sampled 70 min after removal of mimosine. The transfer resulting from a $2 \mathrm{D}$ gel separation of replication intermediates $\left(\sim 3.5 \times 10^{8}\right.$ cell equivalents per gel) was hybridized successively with probe 103 for the gene (see Fig. 1A) or with $12+38$ for the ori- $\beta$ locus. (B) $\Delta$ Pml-lox cells were synchronized as above and sampled at 70 min after removal of mimosine. The transfer was hybridized successively with probe 103 for the gene or $12+38$ for the ori- $\beta$ locus. Note that approximately twice as many intermediates ( $7 \times 10^{8}$ cell equivalents) were loaded in $B$ as in $A$, to attempt to bring the intensity of the single fork arcs up to that observed for the ori- $\beta$ locus in $A$. $(C)$ Replication intermediates were isolated from Pml-lox cells 70 min after removal of mimosine, and the replication intermediates from $\sim 7 \times 10^{8}$ cells were separated on a 2D gel and analyzed by hybridization, using probe 103 to examine the body of the DHFR gene. This high concentration of intermediates allowed us to bring the intensity of the resulting $\mathrm{X}$-ray image approximately up to that of $\Delta \mathrm{Pml}$-lox in $B$.

Importantly, our studies on the DHFR locus show that modulation of origin activity by transcription is not strictly a developmental phenomenon, and can be adjusted acutely by the deletion and restoration of a promoter in somatic cells.

The second effect of deleting the DHFR promoter is a lowered efficiency of initiation in the locus as a whole; this conclusion is based on its failure to complete replication until very late in S phase (Figs. 2C, 4B). One simple explanation might be the larger size of the initiation zone, which now includes the inactive 26-kb DHFR gene: if one or several of the components required to assemble and/or subsequently activate pre-RCs are ratelimiting and somehow compartmentalized, the number of functional complexes actually assembled in any given $S$ period might be substantially reduced. Therefore, those cells in which the origin does not fire in a given $S$ period must wait to be replicated passively from forks emanating from distant origins. By this model, active transcription modulates replication timing not by regulating the time of origin activation, but rather by enhancing the efficiency of initiation at the usual time.

An alternative possibility is that convergent transcription through both the DHFR and 2BE2121 genes propagates a change in chromatin architecture in the intergenic region, possibly mediated by the increase in positive supercoils that accumulate ahead of transcription forks (Liu and Wang 1987; Lee and Garrard 1991). When only 2 BE2121 is being transcribed, the stimulatory effect on initiation in the expanded intergenic region may be abrogated. Presumably, deletion of the 2BE2121 promoter, were it possible, would completely eliminate initiation in the very large template now produced. Both this model and the previous one are supported by the observation that deletion of the central $40 \mathrm{~kb}$ of the intergenic region has no measurable effect on the time of replication of the DHFR locus as a whole, apparently because the frequency of initiations in the truncated spacer actually is increased (Mesner et al. 2003).

Thus, we have demonstrated a role for transcription and/or the local promoter in activating initiation in the DHFR origin in CHO cells, and have additionally shown that transcription plays a central role in defining the boundaries of this origin. Whether this effect is mediated by chromatin remodeling or transcription factors remains to be determined.

\section{Materials and methods}

\section{Cell culture and cell synchrony}

DHFR-deficient cell lines were propagated in Minimal Essential Medium (MEM; Invitrogen) containing 10\% fetal clone II (FCII; Hyclone) supplemented with $100 \mu \mathrm{M}$ hypoxanthine and $16 \mu \mathrm{M}$ thymidine (Invitrogen). CHO cells and DHFR-expressing variants were cultured in MEM/FCII lacking hypoxanthine and thymidine. Synchrony and release were as described (Dijkwel and Hamlin 1995). The peak of initiation in the wild-type DHFR locus occurs between 70 and $100 \mathrm{~min}$ after release from mimosine, and $\mathrm{S}$ phase is complete in 8-9 h.

\section{Construction of cosmid and plasmid donors}

for homologous recombination

Donors for modifying the DHFR locus were constructed from the cosmid cH-2 (Fig. 1D; Looney and Hamlin 1987). A 5.0-kb Xbal fragment located $\sim 800$ bp upstream from the $5^{\prime}$ deletion junction in DG22 was inserted between the AgeI and ApaI sites $\sim 4.0$ and $1.9 \mathrm{~kb}$ upstream from the DHFR-coding sequence in $\mathrm{cH} 2$, respectively. For Swa-lox, RV-lox, Afe-lox, and Pml-lox (the parents of the corresponding deletion variants shown in Fig. $1 \mathrm{~F})$, an oligonucleotide containing a loxP site was cloned immediately $3^{\prime}$ to the inserted 5.0-kb fragment. For lox-Pml-lox, the loxP oligonucleotide was inserted at the PmlI site $\sim 1.3 \mathrm{~kb}$ downstream from the ApaI site. The downstream matched loxP sites were inserted as follows: at the SwaI site in intron 3 for Swa-lox; at the EcoRV site in intron 2 for RV-lox; at the AfeI site in intron 2 for Afe-lox; and at the PmlI site in intron 1 for Pml-lox and lox-Pml-lox. For $\Delta$ Apa-Pml, the plasmid, pBC/0.9 $\mathrm{Pml} / 2$ lox, which contains the 900-bp PmlI fragment flanked by loxP sites, served as the donor (Fig. 1D). To insert the ecdysoneinducible heat-shock promoter (Ecdysone-Inducible Mamma- 
lian Expression System; Invitrogen) into the DHFR promoter region, a loxP-containing oligonucleotide was cloned into a BglII site $5^{\prime}$ to the hormone-response elements (5xE/GREs) in pIND/ hygro (Invitrogen); a 166-bp AvrI-BsmBI fragment containing exon 1 and the first $80 \mathrm{bp}$ of intron 1 of the DHFR gene, along with a loxP site inserted immediately $3^{\prime}$ to it, was cloned into the NheI-EcoRV sites $3^{\prime}$ to the heat-shock promoter.

\section{Generating deletion variants by homologous recombination}

Cosmid donors (10 $\mu \mathrm{g}$ ) digested with AgeI and SalI (Fig. 1D) were transfected into DG22 cells by electroporation as described (Kalejta et al. 1998). Transfectants were plated in MEM containing $10 \%$ FCII supplemented with hypoxanthine and thymidine (HT; $\sim 3-5 \times 10^{6}$ cells per $10-\mathrm{cm}$ culture dish). Then, $48 \mathrm{~h}$ later, the medium was replaced with F12-Special medium lacking hypoxanthine, thymidine, and glycine and supplemented with $10 \%$ Fetal Clone I (Invitrogen). After 8-10 d, surviving colonies were expanded and genomic DNAs were analyzed by Southern hybridizations (probes and diagnostic fragments indicated in Fig. 1). This process yielded Swa-lox, RV-lox, Afe-lox, Pml-lox, and lox-Pml-lox.

To create the desired deletions, these cell lines were transfected with a plasmid expressing the Cre recombinase (Sauer and Henderson 1988), using lipofectamine 2000 (Invitrogen). After $20 \mathrm{~h}$, cells were trypsinized, and 3-5 cells were plated per $10-\mathrm{cm}$ culture dish in MEM/FCII containing HT supplement (MEM/HT). Resulting DHFR-deficient cell lines were selected by replica-plating in F12-Special or on MEM/HT, and expanding those that died on F12-Special. Southern hybridizations identified the resulting $\Delta$ Swa-lox, $\Delta \mathrm{RV}$-lox, $\Delta$ Afe-lox, $\Delta$ Pml- lox, and $\Delta$ lox-Pml-lox cell lines (Fig. 1F). For $\Delta$ Apa-Pml, the donor, $\mathrm{pBC} /$ $0.9 \mathrm{Pml} / 2 \mathrm{lox}$, was transfected into $\Delta$ Pml-lox cells $\left(6 \times 10^{7}\right.$ cells $)$ along with the plasmid expressing Cre, using lipofectamine 2000. Cells were split $20 \mathrm{~h}$ after transfection and plated in MEM/HT containing FCII $\left(6 \times 10^{6}\right.$ cells per $10-\mathrm{cm}$ dish). The medium was replaced with F12-Special $24 \mathrm{~h}$ later, $\mathrm{DHFR}^{+}$colonies were expanded, and DNA was analyzed as above for the appropriate deletion.

To create the cell line with the Drosophila-based heat-shock promoter system, the donor plasmid pIND/hygro/Avr-BsmB/2 lox, the plasmid VgRxR (carrying the genes expressing the inducible hormone along with a zeocin-resistance gene marker), and a Cre-expressing plasmid were cotransfected into $\Delta$ Pml-lox using lipofectamine 2000. Cells were trypsinized $20 \mathrm{~h}$ after transfection and plated at $4-6 \times 10^{6}$ cells per $10-\mathrm{cm}$ dish in MEM/HT containing zeocin $(1000 \mu \mathrm{g} / \mathrm{mL})$. After $6-8 \mathrm{~d}$, surviving $\mathrm{zeo}^{\mathrm{r}}$ colonies were treated with the inducer, ponasterone A ( $5 \mathrm{mM})$, in MEM/HT for $24 \mathrm{~h}$. The medium was replaced with F12-Special medium containing $5 \mathrm{mM}$ ponasterone A to select colonies actively expressing the DHFR gene. The medium with inducer was replaced every $36 \mathrm{~h}$. Genomic DNAs from surviving colonies were analyzed as above.

\section{Two-dimensional gel replicon mapping procedure}

Cells were plated at a density of $4-8 \times 10^{6}$ cells per $15-\mathrm{cm}$ dish, and starved at a density of $4-6 \times 10^{7} /$ dish for $28-32 \mathrm{~h}$. Release into $\mathrm{S}$ phase, isolation of replication intermediates, and $2 \mathrm{D}$ gel analysis were as described (Brewer and Fangman 1987; Dijkwel et al. 1991).

\section{RT-PCR analysis of primary transcripts}

Total RNA from log-phase cells was isolated as described (Chomczynski and Sacchi 1987) from $\sim 6-8 \times 10^{7}$ cells cultured in MEM/HT containing 10\% FCII. To isolate RNAs from early S-phase cells, replicas of those plated for 2D gel analysis were harvested $90 \mathrm{~min}$ after release into $\mathrm{S}$ phase. Then $\sim 20 \mu \mathrm{g}$ of total RNA was treated with $80 \mathrm{U}$ of DNaseI (Roche) in $20 \mathrm{mM}$ Tris$\mathrm{HCl}(\mathrm{pH} 8.4), 2 \mathrm{mM} \mathrm{MgCl} 2,50 \mathrm{mM} \mathrm{KCl}$, and $5 \mathrm{mM}$ DTT for 10 min at $37^{\circ} \mathrm{C}$. The enzyme was inactivated for $5 \mathrm{~min}$ at $75^{\circ} \mathrm{C}$, and the RNA was precipitated with alcohol in the presence of 100 $\mathrm{mM} \mathrm{NaCl}$. cDNA was synthesized using the Thermoscript RTPCR system (Invitrogen) according to the manufacturer's instructions. DNase I-treated RNA was resuspended at $1.5 \mu \mathrm{g} / \mu \mathrm{L}$, and $4.5 \mu \mathrm{g}$ of RNA was used for cDNA synthesis. Reactions were carried out for $45 \mathrm{~min}$ at $50^{\circ} \mathrm{C}$. For PCR reactions, $\sim 20 \%$ of each cDNA synthesis reaction was used; these were carried out using Taq DNA polymerase (Roche) in a RoboCycler Gradient 96 instrument (Stratagene). Denaturation for $2 \mathrm{~min}$ at $95^{\circ} \mathrm{C}$ was followed by 40 cycles of amplification (denaturation for $1 \mathrm{~min}$ at $95^{\circ} \mathrm{C}$, annealing for $1.5 \mathrm{~min}$ at $60^{\circ} \mathrm{C}$, and extension for $1.5 \mathrm{~min}$ at $72^{\circ} \mathrm{C}$ ). PCR products were analyzed on a $1 \%$ agarose gel. Primers for cDNA synthesis and PCR are available upon request.

\section{Acknowledgments}

We thank Pieter A. Dijkwel for the use of the 2D gel data for CHO cells in Figure 2, and the other members of our laboratory for valuable discussions throughout the course of this work. We also thank Lawrence Chasin and Adelaide Carothers (Columbia University) for the gifts of the DG22 and DR- 8 cell lines, respectively. This study was supported by a grant to J.L.H. from the NIH (RO1 GM26108).

The publication costs of this article were defrayed in part by payment of page charges. This article must therefore be hereby marked "advertisement" in accordance with 18 USC section 1734 solely to indicate this fact.

\section{References}

Aladjem, M.I., Groudine, M., Brody, L.L., Dieken, E.S., Fournier, R.E., Wahl, G.M., and Epner, E.M. 1995. Participation of the human $\beta$-globin locus control region in initiation of DNA replication. Science 270: 815-819.

Avner, P. and Heard, E. 2001. X-Chromosome inactivation: Counting, choice and initiation. Nat. Rev. Genet. 2: 59-67.

Azizkhan, J.C., Jensen, D.E., Pierce, A.J., and Wade, M. 1993. Transcription from TATA-less promoters: Dihydrofolate reductase as a model. Crit. Rev. Eukaryot. Gene Expr. 3: 229254.

Beall, E.L., Manak, J.R., Zhou, S., Bell, M., Lipsick, J.S., and Botchan, M.R. 2002. Role for the Drosophila Myb-containing protein complex in site-specific DNA replication. Nature 420: 833-837.

Brewer, B.J. and Fangman, W.L. 1987. The localization of replication origins on ARS plasmids in S. cerevisiae. Cell 51: 463-471.

Buchman, A.R., Lue, N.F., and Kornberg, R.D. 1988. Connections between transcriptional activators, silencers, and telomeres as revealed by functional analysis of a yeast DNAbinding protein. Mol. Cell. Biol. 8: 5086-5099.

Burhans, W.C., Vassilev, L.T., Caddle, M.S., Heintz, N.H., and DePamphilis, M.L. 1990. Identification of an origin of bidirectional DNA replication in mammalian chromosomes. Cell 62: 955-965.

Chomczynski, P. and Sacchi, N. 1987. Single-step method of RNA isolation by acid guanidinium thiocyanate-phenol- 
chloroform extraction. Anal. Biochem. 162: 156-159.

Cohen, S.M., Brylawski, B.P., Cordeiro-Stone, M., and Kaufman, D.G. 2003. Same origins of DNA replication function on the active and inactive human X chromosomes. J. Cell Biochem. 88: 923-931.

Dijkwel, P.A. and Hamlin, J.L. 1995. The Chinese hamster dihydrofolate reductase origin consists of multiple potential nascent-strand start sites. Mol. Cell. Biol. 15: 3023-3031.

Dijkwel, P.A., Vaughn, J.P., and Hamlin, J.L. 1991. Mapping of replication initiation sites in mammalian genomes by twodimensional gel analysis: Stabilization and enrichment of replication intermediates by isolation on the nuclear matrix. Mol. Cell. Biol. 11: 3850-3859.

Dijkwel, P.A., Mesner, L.D., Levenson, V.V., d'Anna, J., and Hamlin, J.L. 2000. Dispersive initiation of replication in the Chinese hamster rhodopsin locus. Exp. Cell Res. 256: 150157.

Dijkwel, P.A., Wang, S., and Hamlin, J.L. 2002. Initiation sites are distributed at frequent intervals in the Chinese hamster dihydrofolate reductase origin of replication but are used with very different efficiencies. Mol. Cell. Biol. 22: 30533065.

Disteche, C.M., Eicher, E.M., and Latt, S.A. 1979. Late replication in an X-autosome translocation in the mouse: Correlation with genetic inactivation and evidence for selective effects during embryogenesis. Proc. Nat1. Acad. Sci. 76: 5234-5238.

Elgin, S.C. and Hood, L.E. 1973. Chromosomal proteins of Drosophila embryos. Biochemistry 12: 4984-4991.

Epner, E., Forrester, W.C., and Groudine, M. 1988. Asynchronous DNA replication within the human $\beta$-globin gene locus. Proc. Natl. Acad. Sci. 85: 8081-8085.

Farnham, P.J. and Schimke, R.T. 1986. In vitro transcription and delimitation of promoter elements of the murine dihydrofolate reductase gene. Mol. Cell. Biol. 6: 2392-2401.

Ferguson, B.M. and Fangman, W.L. 1992. A position effect on the time of replication origin activation in yeast. Cell 68: 333-339.

Forrester, W.C., Epner, E., Driscoll, M.C., Enver, T., Brice, M., Papayannopoulou, T., and Groudine, M. 1990. A deletion of the human $\beta$-globin locus activation region causes a major alteration in chromatin structure and replication across the entire $\beta$-globin locus. Genes \& Dev. 4: 1637-1649.

Gilbert, D.M. 2001. Making sense of eukaryotic DNA replication origins. Science 294: 96-100.

Goldman, M.A., Holmquist, G.P., Gray, M.C., Caston, L.A., and $\mathrm{Nag}, \mathrm{A} .1984$. Replication timing of genes and middle repetitive sequences. Science 224: 686-692.

Goren, A. and Cedar, H. 2003. Replicating by the clock. Nat. Rev. Mol. Cell Biol. 4: 25-32.

Hand, R. 1978. Eucaryotic DNA: Organization of the genome for replication. Cell 15: 317-325.

Hatton, K.S., Dhar, V., Brown, E.H., Iqbal, M.A., Stuart, S., Didamo, V.T., and Schildkraut, C.L. 1988. Replication program of active and inactive multigene families in mammalian cells. Mol. Cell. Biol. 8: 2149-2158.

Heintz, N.H. 1992. Transcription factors and the control of DNA replication. Curr. Opin. Biol. 4: 459-467.

Heintz, N.H. and Hamlin, J.L. 1982. An amplified chromosomal sequence that includes the gene for dihydrofolate reductase initiates replication within specific restriction fragments. Proc. Natl. Acad. Sci. 79: 4083-4087.

Heintz, N.H., Milbrandt, J.D., Greisen, K.S., and Hamlin, J.L. 1983. Cloning of the initiation region of a mammalian chromosomal replicon. Nature 302: 439-441.

Holmquist, G.P. 1987. Role of replication time in the control of tissue-specific gene expression. Am. J. Human Genet. 40:
$151-173$

Hyrien, O., Maric, C., and Mechali, M. 1995. Transition in specification of embryonic metazoan DNA replication origins. Science 270: 994-997.

Jin, Y., Yie, T.A., and Carothers, A.M. 1995. Non-random deletions at the dihydrofolate reductase locus of Chinese hamster over cells induced by $\alpha$-particles simulating radon. Carcinogenesis 16: 1981-1991.

Kalejta, R.F., Li, X., Mesner, L.D., Dijkwel, P.A., Lin, H.B., and Hamlin, J.L. 1998. Distal sequences, but not ori- $\beta / O B R-1$, are essential for initiation of DNA replication in the Chinese hamster DHFR origin. Mol. Cell 2: 797-806.

Keohane, A.M., O'Neill, L.P., Belyaev, N.D., Lavender, J.S., and Turner, B.M. 1996. X-Inactivation and histone H4 acetylation in embryonic stem cells. Dev. Biol. 180: 618-630.

Kim, S.-M., Dubey, D.D., and Huberman, J.A. 2003. Early-replicating heterochromatin. Genes \& Dev. 17: 330-335.

Kobayashi, T., Rein, T., and DePamphilis, M.L. 1998. Identification of primary initiation sites for DNA replication in the hamster dihydrofolate reductase gene initiation zone. Mol. Cell. Biol. 18: 3266-3277.

Lee, M.S. and Garrard, W.T. 1991. Transcription-induced nucleosome 'splitting': An underlying structure for DNase I sensitive chromatin. EMBO I. 10: 607-615.

Leu, T.H. and Hamlin, J.L. 1989. High-resolution mapping of replication fork movement through the amplified dihydrofolate reductase domain in $\mathrm{CHO}$ cells by in-gel renaturation analysis. Mol. Cell. Biol. 9: 523-531.

Lin, S. and Kowalski, D. 1997. Functional equivalency and diversity of cis-acting elements among yeast replication origins. Mol. Cell. Biol. 17: 5473-5484.

Liu, L.F. and Wang, J.C. 1987. Supercoiling of the DNA template during transcription. Proc. Natl. Acad. Sci. 84: 7024-7027.

Looney, J.E. and Hamlin, J.L. 1987. Isolation of the amplified dihydrofolate reductase domain from methotrexate-resistant Chinese hamster ovary cells. Mol. Cell. Biol. 7: 569-577.

Lunyak, V.V., Ezrokhi, M., Smith, H.S., and Gerbi, S.A. 2002. Developmental changes in the Sciara II/9A initiation zone for DNA replication. Mol. Cell. Biol. 22: 8426-8437.

Mesner, L.D., Li, X., Dijkwel, P.A., and Hamlin, J.L. 2003. The dihydrofolate reductase origin of replication does not contain any nonredundant genetic elements required for origin activity. Mol. Cell. Biol. 23: 804-814.

Pelizon, C., Diviacco, S., Falaschi, A., and Giacca, M. 1996. High-resolution mapping of the origin of DNA replication in the hamster dihydrofolate reductase gene domain by competitive PCR. Mol. Cell. Biol. 16: 5358-5364.

Raghuraman, M.K., Winzeler, E.A., Collingwood, D., Hunt, S., Wodicka, L., Conway, A., Lockhart, D.J., Davis, R.W., Brewer, B.J., and Fangman, W.L. 2001. Replication dynamics of the yeast genome. Science 294: 115-121.

Rhoads, D.D. and Roufa, D.J. 1991. Molecular evolution of the mammalian ribosomal protein gene, RPS14. Mol. Biol. Evol. 8: $503-514$.

Sasaki, T., Sawado, T., Yamaguchi, M., and Shinomiya, T. 1999. Specification of regions of DNA replication initiation during embryogenesis in the 65-kilobase DNA pol $\alpha$-dE2F locus of Drosophila melanogaster. Mol. Cell. Biol. 19: 547-555.

Sauer, B. and Henderson, N. 1988. Site-specific DNA recombination in mammalian cells by the Cre recombinase of bacteriophage P1. Proc. Natl. Acad. Sci. 85: 5166-5170.

Schubeler, D., Scalzo, D., Kooperberg, C., van Steensel, B., Delrow, J., and Groudine, M. 2002. Genome-wide DNA replication profile for Drosophila melanogaster: A link between transcription and replication timing. Nat. Genet. 32: 438-442.

Selig, S., Okumura, K., Ward, D.C., and Cedar, H. 1992. Delin- 
Saha et al.

eation of DNA replication time zones by fluorescence in situ hybridization. EMBO J. 11: 1217-1225.

Sharma, K., Weinberger, M., and Huberman, J.A. 2001. Roles for internal and flanking sequences in regulating the activity of mating-type-silencer-associated replication origins in Saccharomyces pombe. Genetics 159: 35-45.

Shiokawa, K, Misumi, Y., and Yamana, K. 1981. Demonstration of rRNA synthesis in pre-gastrula embryos of Xenopus laevis. Dev. Growth Diff. 23: 579-587.

Simon, I., Tenzen, T., Mostoslavsky, R., Fibach, E., Lande, L., Milot, E., Gribnau, J., Grosveld, F., Fraser, P., and Cedar, H. 2001. Developmental regulation of DNA replication timing at the human $\beta$ globin locus. EMBO J. 20: 6150-6157.

Simon, J.J. and Cedar, H. 1996. Temporal order of DNA replication. In DNA replication in eukaryotic cells (ed. M. DePamphilis), pp. 387-408. Cold Spring Harbor Laboratory Press, Cold Spring Harbor, NY.

Snyder, M., Sapolsky, R.J., and Davis, R.W. 1988. Transcription interferes with elements important for chromosome maintenance in Saccharomyces cerevisiae. Mol. Cell. Biol. 8: 2184-2194.

Stevenson, J.B. and Gottschling, D.E. 1999. Telomeric chromatin modulates replication timing near chromosome ends. Genes \& Dev. 13: 146-151.

Su, W., Middleton, T., Sugden, B., and Echols, H. 1991. DNA looping between the origin of replication of Epstein-Barr virus and its enhancer site: Stabilization of an origin complex with Epstein-Barr nuclear antigen 1. Proc. Nat1. Acad. Sci. 88: 10870-10874.

Taljanidisz, J., Popowski, J., and Sarkar, N. 1989. Temporal order of gene replication in Chinese hamster ovary cells. Mol. Cell. Biol. 9: 2881-2889.

Urlaub, G., Kas, E., Carothers, A.M., and Chasin, L.A. 1983. Deletion of the diploid dihydrofolate reductase locus from cultured mammalian cells. Cell 33: 405-412.

van der Vliet, P.C. 1996. Roles of transcription factors in DNA replication. In DNA replication in eukaryotic cells (ed. M. DePamphilis), pp. 87-118. Cold Spring Harbor Laboratory Press, Cold Spring Harbor, NY.

Vaughn, J.P., Dijkwel, P.A., and Hamlin, J.L. 1990. Replication initiates in a broad zone in the amplified $\mathrm{CHO}$ dihydrofolate reductase domain. Cell 61: 1075-1087.

Walker, S.S., Malik, A.K., and Eisenberg, S. 1991. Analysis of the interactions of functional domains of a nuclear origin of replication from Saccharomyces cerevisiae. Nucleic Acids Res. 19: 6255-6262.

Wang, S., Dijkwel, P.A., and Hamlin, J.L. 1998. Lagging-strand, early-labelling, and two-dimensional gel assays suggest multiple potential initiation sites in the Chinese hamster dihydrofolate reductase origin. Mol. Cell. Biol. 18: 39-50.

Weintraub, H., Larsen, A., and Groudine, M. 1981. $\alpha$-Globingene switching during the development of chicken embryos: Expression and chromosome structure. Cell 24: 333-344.

Wu, J.R. and Gilbert, D.M. 1996. A distinct $G_{1}$ step required to specify the Chinese hamster DHFR replication origin. Science 271: 1270-1272.

Wyrick, J.J., Holstege, F.C., Jennings, E.G., Causton, H.C., Shore, D., Grunstein, M., Lander, E.S., and Young, R.A. 1999. Chromosomal landscape of nucleosome-dependent gene expression and silencing in yeast. Nature 402: 418-421.

Yoshida, C., Tokumasu, F., Hohmura, K.I., Bungert, J., Hayashi, N., Nagasawa, T., Engel, J.D., Yamamoto, M., Takeyasu, K., and Igarashi, K. 1999. Long range interaction of cis-DNA elements mediated by architectural transcription factor Bach1. Genes Cells 4: 643-655. 


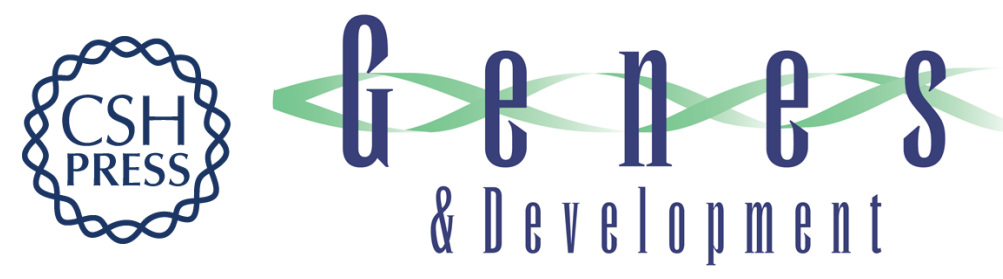

\section{The promoter of the Chinese hamster ovary dihydrofolate reductase gene regulates the activity of the local origin and helps define its boundaries}

Swati Saha, Yujie Shan, Larry D. Mesner, et al.

Genes Dev. 2004, 18:

Access the most recent version at doi:10.1101/gad.1171404

\section{References This article cites 62 articles, 33 of which can be accessed free at: http://genesdev.cshlp.org/content/18/4/397.full.htmI\#ref-list-1}

\section{License}

Email Alerting

Service

Receive free email alerts when new articles cite this article - sign up in the box at the top right corner of the article or click here.

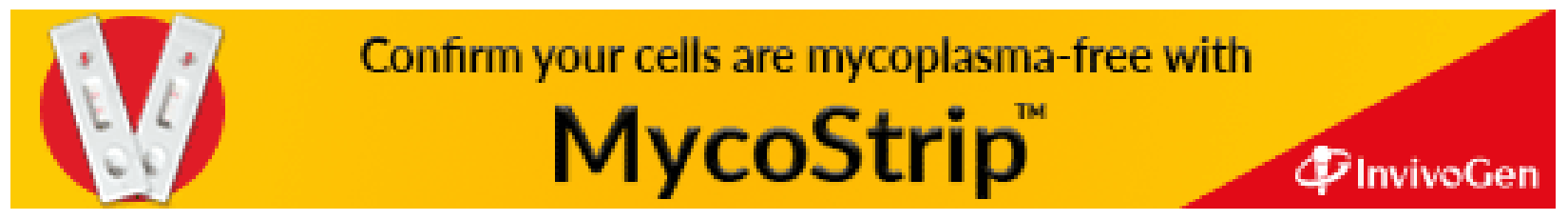

